\title{
A Comprehensive Numerical Study on Effects of Natural Gas Composition on the Operation of an $\mathrm{HCCl}$ Engine
}

\author{
O. Jahanian* and S.A. Jazayeri \\ Department of Mechanical Engineering, K. N. Toosi University of Technology, P.O. Box 19395-1999, Tehran - Iran \\ e-mail: o_jahanian@alborz.kntu.ac.ir - jazayeri@kntu.ac.ir \\ * Corresponding author
}

\begin{abstract}
Résumé - Une étude numérique complète sur les effets de la composition du gaz naturel carburant sur le réglage d'un moteur HCCI - Le moteur HCCI (Homogeneous Charge Compression Ignition, ou à allumage par compression d'une charge homogène) est une idée prometteuse pour réduire la consommation de carburant et les émissions polluantes. Le gaz naturel, considéré généralement comme un carburant propre, est un choix approprié pour les moteurs HCCI en raison de sa capacité à former avec l'air un mélange homogène. Cependant, la composition du gaz naturel influe fortement sur les caractéristiques d'auto-inflammation du mélange dans le cylindre et la performance du moteur HCCI. Cet article met l'accent sur l'influence de la composition du gaz naturel sur le fonctionnement du moteur en mode HCCI. Six différentes compositions de gaz naturel (y compris le méthane pur) ont été examinées pour étudier les performances du moteur au moyen d'un modèle thermo-cinétique zéro-dimensionnel. Le code de simulation inclut la cinétique chimique détaillée de la combustion du gaz naturel, y compris le mécanisme étendu de Zeldovich pour évaluer les émissions de $\mathrm{NO}_{x}$. Les résultats ont été validés par comparaison avec des données expérimentales provenant d'autres travaux. La richesse et le taux de compression ont été maintenus constants, mais les effets de la vitesse du moteur et de la température initiale du mélange ont été étudiés. Les résultats montrent que la valeur maximale de la pression dans le cylindre et la température dépendent du nombre Wobbe du carburant. En outre, la puissance indiquée du moteur est linéairement liée au nombre Wobbe du carburant. Le travail indiqué brut, la pression moyenne indiquée brute et les $\mathrm{NO}_{x}$ ont aussi été utilisés pour comparer les performances du moteur utilisant des carburants de compositions différentes.
\end{abstract}

\footnotetext{
Abstract - A Comprehensive Numerical Study on Effects of Natural Gas Composition on the Operation of an HCCI Engine - Homogeneous Charge Compression Ignition (HCCI) engine is a promising idea to reduce fuel consumption and engine emissions. Natural Gas (NG), usually referred as clean fuel, is an appropriate choice for HCCI engines due to its suitable capability of making homogenous mixture with air. However, varying composition of Natural Gas strongly affects the auto-ignition characteristics of in-cylinder mixture and the performance of the HCCI engine. This paper has focused on the influence of Natural Gas composition on engine operation in HCCI mode. Six different compositions of Natural Gas (including pure methane) have been considered to study the engine performance via a thermo-kinetic zero-dimensional model. The simulation code covers the detailed chemical kinetics of Natural Gas combustion, which includes Zeldovich extended mechanism to evaluate $\mathrm{NO}_{x}$ emission. Validations have been made using experimental data from other works to
} 
ensure the accuracy needed for comparison study. The equivalence ratio and the compression ratio are held constant but the engine speed and mixture initial temperature are changed for comparison study. Results show that the peak value of pressureltemperature of in-cylinder mixture is dependent of fuel Wobbe number. Furthermore, engine gross indicated power is linearly related to fuel Wobbe number. Gross indicated work, gross mean effective pressure, and $\mathrm{NO}_{x}$ are the other parameters utilized to compare the performance of engine using different fuel compositions.

\section{INTRODUCTION}

Recent developments in internal combustion engine technology have been done under consideration of two important facts; the first one is shortage of crude oil resources and its instable global market, the other is enhancement of environmental regulations and tightening legislations. There are two main strategies to satisfy these demands: using alternative fuels other than crude oil products and switching to promising combustion technologies such as HCCI engines [1-4]. Onishi et al. [5] firstly represented the main concept of HCCI in 1979 for two-stroke engines. They figured out that it is possible to reduce engine emissions and fuel consumption by compressing a homogenous fuel/air mixture until it reaches to the auto-ignition point. This idea was named as Active Thermo-Atmospheric Combustion (ATAC) and rapidly developed by Noguchi et al [6]. They showed the advantages of this idea for part-load conditions. Najt et al [7] utilized this concept in four-stroke engines and finally in 1989 Thring [8] named it as HCCI.

The HCCI combustion process verily induces a premixed fuel/air mixture into the cylinder at lean equivalence ratios [9]. The homogenous fuel/air mixture is compressed within the cylinder until ignition occurs. This auto-ignition makes a very rapid combustion phase where all heat is released approximately in 5 to 15 Crank Angle degrees (CA). This rate of heat release is controlled with a highly diluted mixtures using air or Exhaust Gas Residual (EGR). The HCCI concept affords the use of elevated compression ratios (approximately 17-20:1), unlike in SI engines, which are susceptible to knock. The combination of lean burning and high expansion ratios contributes to high thermal efficiencies that can approach 45\% [10]. HCCI engines have demonstrated very low emissions of Oxides of Nitrogen $\left(\mathrm{NO}_{x}\right)$ and Particulate Matter (PM), as well as high thermal efficiency at part load. However, there are some difficulties in applying HCCI combustion to internal combustion engines. Ignition timing control and homogenous mixture preparation are the main difficulties of HCCI engines [11].

Natural Gas (NG) fuel demonstrates minimal mixture preparation requirements, and is chemically very stable. It is well suited to the HCCI combustion concept. NG exhibits a relatively simple molecular structure, which reacts to yield far less intermediate compounds as well as a low carbon to hydrogen ratio that result in reduced harmful exhaust gas emissions. Its high ignition resistance when coupled with lean fuel/air mixtures affords the use of elevated compression ratios without pre-ignition of the charge [10].

Moreover, $\mathrm{NG}$ is relatively less expensive in many countries and it has supply advantages in time, over gasoline and diesel fuel. NG is favored as a clean fuel for motor vehicles especially in urban areas [12]. The technical advantages of Natural Gas include extremely low photochemical reactivity, enclosed fueling system which results in low fuel leak to atmosphere, reduced emissions resulting from cold-start and low-temperature operation, due to the elimination of cold mixture enrichment, and possibility of using fuel efficient and lean-burn technology [12]. Typically, the NG composition includes methane with small amounts of ethane, propane, butane, carbon monoxide, nitrogen, and other trace components. The composition varies depending on NG source field. This variation affects on the operation of the NG fueled engines. Many researchers, focused on this phenomena [13-23]. One of the major concerns with varying NG composition in HCCI engines is Start of Combustion (SOC).

In this paper, a zero-dimensional single zone thermo-kinetic model is developed to simulate the operation of an HCCI engine. The model uses GRI-Mech 3.0 [24] mechanism for detail study on NG combustion including its varying composition. High computational speed, and appropriate precision for calculating parameters such as SOC and in-cylinder temperature/pressure trends are the main reasons of using this model. In the next sections, the developed model is described. This model is validated with experimental results. The final section includes the results on engine performance and combustion characteristics via different NG compositions for a Volvo TD 100 engine.

\section{MODEL DESCRIPTION}

In this study, a zero-dimensional single zone thermo-kinetic model is developed. This model has been validated and used in our previous studies $[2,3,25,26]$. We have used MATLAB ${ }^{\circledast}$ programming environment to develop the code and CANTERA $^{\oplus}$ module to gain the thermo-chemical properties of reacting gas mixture. The model uses detailed chemical kinetics while neglecting the effects of transport phenomena because HCCI combustion process is mainly dominated by chemistry without any evidence of flame propagation. 


\section{THERMO-KINETIC MODELING APPROACH}

The model assumptions can be described as below:

- the engine is a four-stroke HCCI;

- only the closed cycle from Inlet Valve Closing (IVC) to Exhaust Valve Opening (EVO) is considered in the model;

- the whole combustion chamber is defined as a uniform temperature/pressure zone;

- all the components in the combustion chamber are treated as perfect gas;

- blow-by is neglected;

- the fuel/air mixture at IVC is completely homogenous;

- a modified Woschni model [27] calculates the heat transfer to cylinder wall.

For exact study on combustion phenomena, detail chemical kinetics has been considered in the model. The deailed mechanism used in this paper includes 325 primary reactions with 53 chemical species. As this mechanism covers the combustion reactions of methane, ethane, propane, and other components of NG and includes the extended Zeldovich mechanism to calculate $\mathrm{NO}_{x}$ emissions, it is suitable for investigation on NG combustion, especially with varying composition such as ethane and propane.

\subsection{Governing Equations}

In a zero-dimensional model, the whole combustion chamber is considered as a control volume. The energy conservation equation is solved for this zone. Figure 1 shows the terms of energy conservation equation in this system.

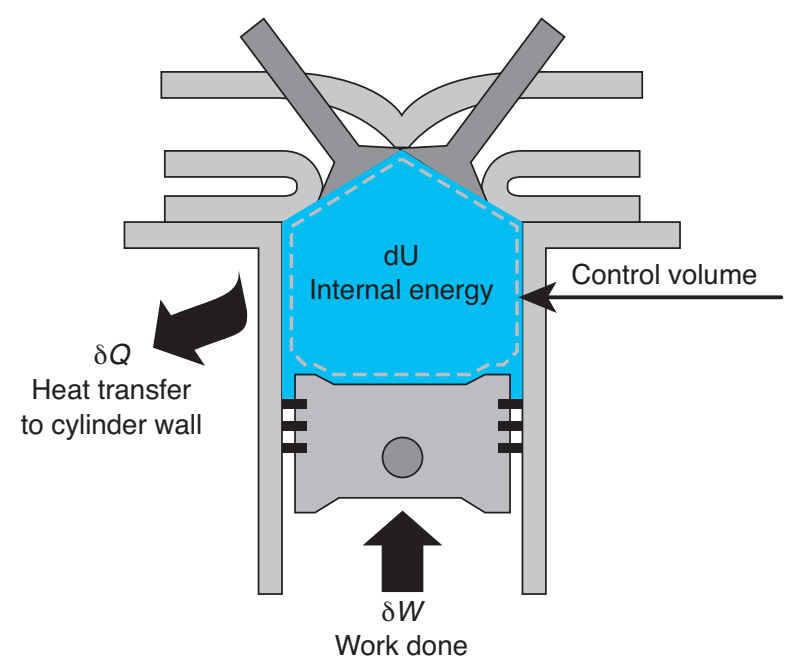

Figure 1

Control volume in the zero-dimensional single zone model.
The energy conservation equation can be described as:

$$
\delta Q-\delta W=d U
$$

Equation (1) can be rewritten for the mixture of several chemical species as:

$$
\delta Q-P d V=m d u+m \sum_{i=1}^{N_{s}} u_{i} d y_{i}
$$

As $Q$ is only due to heat transfer to cylinder wall and the mixture is a perfect gas:

$$
\frac{d q}{d t}-P \frac{d V}{d t}=m C_{v} \frac{d T}{d t}+m \sum_{i=1}^{N_{s}} u_{i} \frac{d y_{i}}{d t}
$$

By separating the temperature terms, the first differential equation of the model can be obtained:

$$
\frac{d T}{d t}=\frac{\frac{1}{V}\left(\frac{d q}{d t}-P \frac{d V}{d t}\right)-\rho \sum_{i=1}^{N_{s}} u_{i} \frac{d y_{i}}{d t}}{\rho C_{v}}
$$

This equation describes that the in-cylinder temperature variations, originate from two sources:

- energy transfer through system border;

- variation in system chemical composition.

The mass conservation equation is the next frame that should be considered after the energy conservation. The mass conservation equation in chemical reacting systems is defined as the conservation of chemical elements. The rate of mole fraction variation of chemical species can be computed as:

$$
\frac{d y_{i}}{d t}=\frac{M_{i} \dot{\omega}_{i}}{\rho}
$$

Equation (5) should be written for every chemical component and these set of equations must be solved simultaneously with Equation (4). A detailed chemical kinetics mechanism is needed to determine the production/consumption rate of each chemical component $\left(\dot{\omega}_{i}\right)$. Section 2.2 thoroughly describes the chemical kinetics.

Now, there is a need for another differential equation beside temperature and species masses to enclose the differential equations system. This equation defines the rate of variation in combustion chamber volume [28] via a slider-crank formula:

$$
V=V_{c}\left(1+\frac{r_{c}-1}{2}\left(R+1-\cos \theta-\sqrt{R^{2}-\sin ^{2} \theta}\right)\right)
$$

\subsection{Chemical Kinetics}

The Mass Action rule [29] explains that the reaction rate in each direction depends on reactants' concentration and their stoichiometric coefficients. Therefore, the reaction rate is:

$$
R R=k_{f}[A]^{a}[B]^{b}-k_{b}[C]^{c}
$$


Symbol $[A]$ means the molar concentration of the component $A$, and the rate constant $k$ is determined by Arrhenius relation [29] in Equation (8). Indices $f$ and $b$ represent forward and backward direction in an equilibrium reaction:

$$
k=A_{A r} T^{\beta} \exp \left(\frac{-E_{a}}{R_{u} T}\right)
$$

Each mechanism consists some primary reactions which are either simple or with third body. A simple primary reaction can be assumed as:

$$
\sum_{k=1}^{N_{s}} v_{k, i}^{\prime} S_{i} \rightleftarrows \sum_{k=1}^{N_{s}} v^{\prime \prime}{ }_{k, i} S_{i} \quad i=1,2, \ldots, N_{R}
$$

For each simple primary reaction, the reaction rate equation turns to:

$$
R R_{i}=k_{f, i} \prod_{k=1}^{N_{s}}\left[S_{k}\right]^{v_{k, i}^{\prime}}-k_{b, i} \prod_{k=1}^{N_{s}}\left[S_{k}\right]^{v_{k, i}^{\prime \prime}}
$$

Some primary reactions need a third body to be done. As the concentration of the third body effects the reaction rate, it differs from Equation (10) and should be written as:

$$
\sum_{k=1}^{N_{s}} v_{k, i}^{\prime} S_{i}+T B \rightleftarrows \sum_{k=1}^{N_{s}} v_{k, i}^{\prime \prime} S_{i}+T B
$$

The third body concentration includes the concentrations of all species due to their enhance factor. Therefore, the reaction rate for these types of primary reactions is:

$$
R R_{i}=\left(\sum_{k=1}^{N_{s}} a_{k, i}\left[T B_{k}\right]\right) \times\left(k_{f, i} \prod_{k=1}^{N_{s}}\left[S_{k}\right]^{v_{k, i}}-k_{b, i} \prod_{k=1}^{N_{s}}\left[S_{k}\right]^{v_{k, i}^{\prime \prime}}\right)
$$

The coefficients can be obtained from different sources describing reaction mechanisms [30]. So the production/ consumption rate of each chemical component can be calculated as:

$$
\dot{\omega}_{k}=\sum_{i=1}^{N_{R}} R R_{i}\left(v_{k, i}^{\prime}-v_{k, i}^{\prime \prime}\right)
$$

\subsection{Heat Transfer Model}

For defining $d q / d t$, it is common to use Woschni heat transfer model for traditional internal combustion engines, but due to rapid combustion period of HCCI engines, a modified relation [27] has been used in this paper. This modified model describes:

$$
\frac{d q}{d t}=h A\left(T-T_{w}\right)
$$

where the convection heat transfer coefficient is:

$$
\begin{gathered}
h=129.8 L^{-0.2} P^{0.8} T^{-0.73}\left(2.28 S_{p}+f(P)\right)^{0.8} \\
f(P)=3.34 \times 10^{-4} \frac{V_{d} T_{r}}{P_{r} V_{r}}\left(P-P_{m o t}\right)
\end{gathered}
$$

\section{SELECTION OF NG COMPOSITIONS}

Six different kinds of NG having various compositions are selected to investigate the operations of an HCCI engine characteristic. These kinds include three common compositions used in Iran, South Korea, and USA, besides two blends of light hydrocarbons, and pure methane gas for comparison. The different NG compositions are referred to as Gas A, B, $\mathrm{C}, \mathrm{D}, \mathrm{E}$, and $\mathrm{F}$ in this paper. The compositions of these gases are tabulated in Table 1. The table also includes molar weight, specific gravity, Low Heating Value $(L H V)$, Wobbe Number $(W N)$, and stoichiometric Air/Fuel ratio of the fuels. The procedure for calculating values in Table 1 is described in Appendix A.

\section{MODEL VALIDATION}

The developed zero-dimensional single zone model has been validated in previous work for two types of engine Caterpillar 3500 and Volvo TD 100 using "Gas A" and "Gas B" as fuel [3]. As studies of this paper have been done for single cylinder Volvo TD 100 engine, the simulation code has been calibrated by setting the parameters for this engine and two other comparisons for different fuel compositions and operational conditions have been presented to ensure the model accuracy. The engine's geometry is shown in Table 2.

In case $\mathrm{A}$, the engine is operating at 18:1 compression ratio and using "Gas F" as fuel with equivalence ratio of 0.4. The experimental data for this case is obtained from Reference [33]. The compression ratio is set to $19.8: 1$ for case B using "Gas B" as fuel with equivalence ratio of 0.3. This set up is selected due to experimental data of Reference [10]. "Gas B" and "Gas F" are chosen as the fuel, in purpose to cover the full range of NG composition in this study. Furthermore, an optimized mechanism is needed to trace the NG composition effects. "GRI-Mech 3.0 is an optimized mechanism designed to model Natural Gas combustion, including NO formation and re-burn chemistry. The optimization process is designed to provide sound basic kinetics, which also furnish the best combined modeling predictability of basic combustion properties. Improvements were made in the categories of updating the kinetics with recent literature results, including some, new and improved target experiments to the optimization, expanding the mechanism and target selection, and examining the sensitivity to the thermodynamics" [24].

Figures 2 and 3 show the pressure trends in these two cases. As shown in Figures 2 and 3, the model can predict the operational conditions of an HCCI engine with acceptable uncertainty. Similar to all single zone models, the peak cylinder pressure is higher than the experimental results. This is because of:

- the homogeneity of combustion chamber is the main assumption of single zone models. But in real cases, there 
TABLE 1

Different blends of natural gas

\begin{tabular}{|c|c|c|c|c|c|c|}
\hline & Gas A [10] & Gas B [10] & Gas C [31] & Gas D [31] & Gas E [21] & Gas F [32] \\
\hline Methane & 100 & 99 & 97.5 & 95.85 & 90.6 & 88.7 \\
\hline Ethane & 0 & 0 & 2 & 3.44 & 6.54 & 7.2 \\
\hline Propane & 0 & 1 & 0.5 & 0.71 & 2.66 & 3.6 \\
\hline Nitrogen & 0 & 0 & 0 & 0 & 0.2 & 0.5 \\
\hline Molar weight & 16.04 & 16.32 & 16.46 & 16.72 & 17.73 & 18.12 \\
\hline Specific gravity & 0.553 & 0.563 & 0.568 & 0.577 & 0.612 & 0.626 \\
\hline$L H V(\mathrm{MJ} / \mathrm{kg})$ & 50.03 & 49.93 & 49.89 & 49.80 & 49.35 & 49.02 \\
\hline Wobbe Number & 43.81 & 44.11 & 44.26 & 44.53 & 45.43 & 45.63 \\
\hline A/F mole@ & 9.522 & 9.665 & 9.736 & 9.869 & 10.345 & 10.503 \\
\hline Note & Pure methane & $\begin{array}{c}\text { Methane/propane } \\
\text { blend }\end{array}$ & $\begin{array}{c}\text { Methane/ethane } \\
\text { blend }\end{array}$ & $\begin{array}{l}\text { Common } \\
\text { in USA }\end{array}$ & $\begin{array}{l}\text { Common } \\
\text { in South Korea }\end{array}$ & $\begin{array}{c}\text { Common } \\
\text { in Iran }\end{array}$ \\
\hline
\end{tabular}

TABLE 2

Geometry of the Volvo TD 100 engines

\begin{tabular}{l|c}
\hline & Volvo TD 100 \\
\hline Bore $(\mathrm{mm})$ & 120.65 \\
\hline Stroke $(\mathrm{mm})$ & 140 \\
\hline Rod length $(\mathrm{mm})$ & 260 \\
\hline Compression ratio & $18[33]$ and19.8 [10] \\
\hline IVC $(\mathrm{CA}, \mathrm{ABDC})$ & 39 \\
\hline EVO $(\mathrm{CA}, \mathrm{BBDC})$ & 1000 \\
\hline Engine speed (rpm) & 13 \\
\hline
\end{tabular}

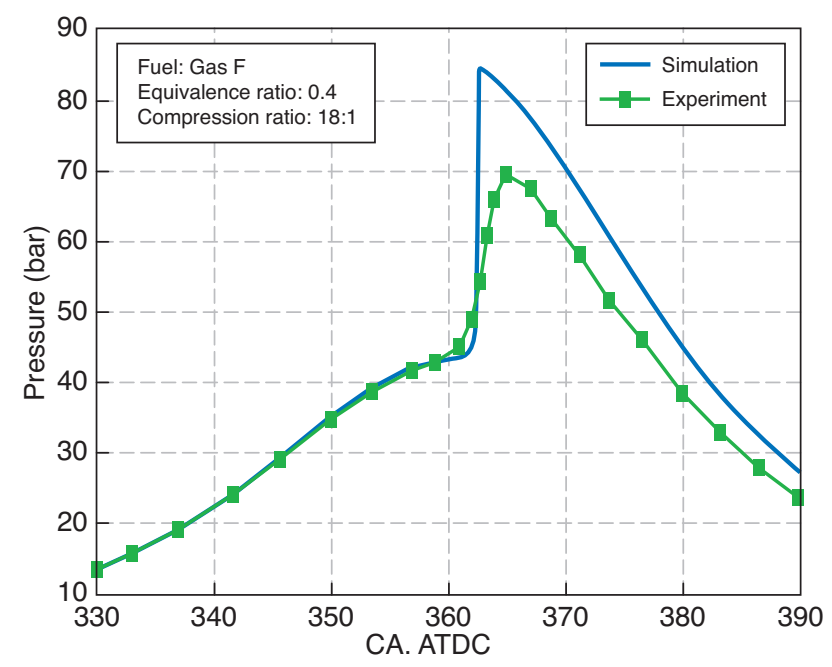

Figure 2

Pressure trend versus Crank Angle (case A). are some in-homogeneities in fuel/air mixture at IVC and also during the engine strokes, the near-wall areas has lower temperature because of heat transfer to cylinder wall;

- single zone HCCI models, neglect blow-by, and the unburned amount of fuel in crevices so the pressure is over predicted in the simulation.

In order to compare the simulation and experiment, SOC for both experimental and simulated engine cycles is calculated by the third derivative of the pressure trace due to the Crank Angle. It is suggested that the combustion starts when

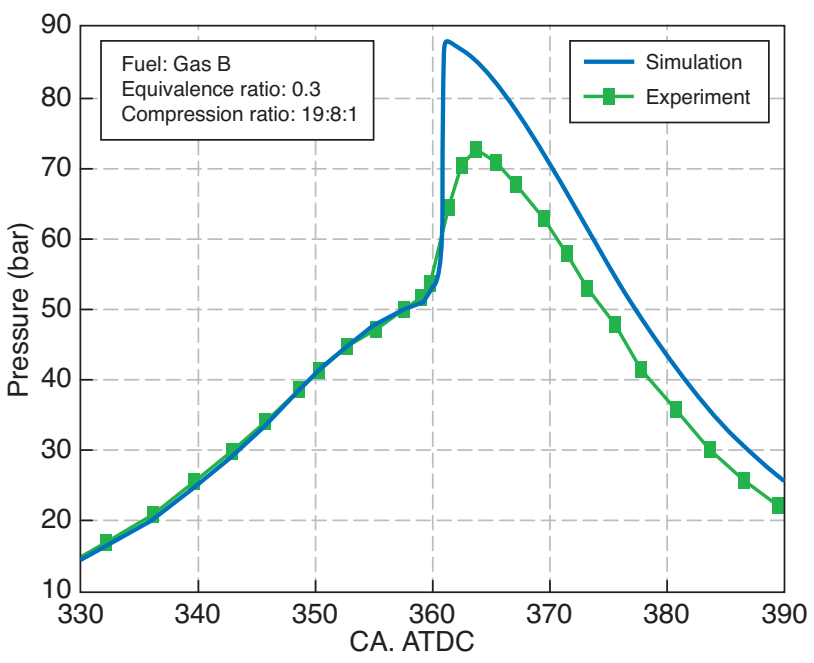

Figure 3

Pressure trend versus Crank Angle (case B). 
the third derivative of the pressure trace reaches a specified value $[34,35]$.

$$
\left.\frac{d^{3} P}{d \theta^{3}}\right|_{S O C}=0.25 \text { bar.CAD }{ }^{-3}
$$

In case $\mathrm{A}$, there is only $0.5 \mathrm{CA}$ difference between experiment and simulation results. Experiment shows 361.7 CA for SOC and simulation predicts it at 362.2 CA. The difference increases to $1.8 \mathrm{CA}$ in case $\mathrm{B}$ where experimental SOC occurs at 360.9 CA but simulation evaluates it at $362.7 \mathrm{CA}$. These comparisons demonstrate that the model can predict SOC with appropriate accuracy.

Due to importance of relative variations of parameters in comparison studies, the global inaccuracy of the single zone models can be neglected [4] and the developed model is well suited for this purpose. Single zone model are widely used because of their low computational requirements and accurate prediction of SOC and $\mathrm{NO}_{x}[3,10,36,37]$.

\section{RESULTS AND DISCUSSIONS}

Simulations have been performed to study the effects of Natural Gas composition on the engine performance in two different aspects. First, the engine performance characteristics with different fuels have been investigated under different initial temperature conditions. In the second section, the study has been done through different engine speeds. All the simulations are done for the introduced engine with compression ratio of 18:1, 0.9 bar pressure at IVC, and equivalence ratio of 0.4 . Other parameters are presented for each specified case.

\subsection{Effect of Initial Temperature}

Figure 4 shows pressure trend near TDC for different fuel types in three different initial temperatures. In Figure 4a, the temperature at IVC is set to $405 \mathrm{~K}$.

Although the main component of Natural Gas is methane, but usually start of combustion in Natural Gas HCCI engines depends on other components such as ethane and propane, which ignites earlier in lower temperature. Lower auto-ignition temperatures of these components are related to oxidation mechanism and $\mathrm{C}-\mathrm{H}$ bond energies. This is discussed in Appendix B.

Existence of heavier hydrocarbons in Natural Gas leads to auto-ignition in such a condition that pure methane does not ignite. This figure shows that while fuels with high content of methane (Gas A, B and C) do not ignite; other fuel that have more ethane and propane in their composition will ignite.
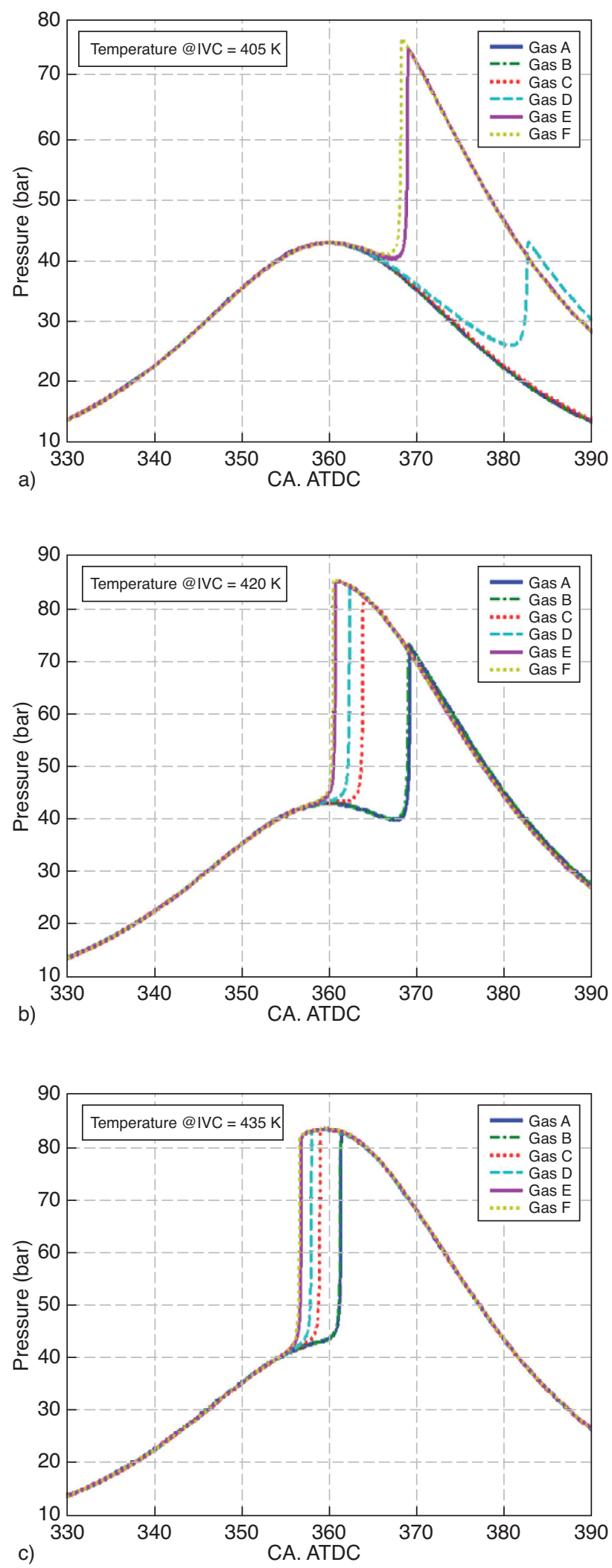

Figure 4

Pressure trend near TDC for different gas fuels at different initial temperature. 
By increasing initial temperature as shown in Figure 4b, all fuels will ignite with different SOC. The figures exactly show the difference between SOC and pressure trend for different fuels. Fuels with more propane contents ignite earlier. The maximum pressure of engine using Gas $\mathrm{F}$ as fuel is about 2.8 bar higher than the one using Gas $\mathrm{C}$ and about 12.6 bar higher than the one using Gas A. The maximum pressure value will increase if the combustion occurs earlier. The fuel with higher percentage of ethane and propane, ignite earlier so they have higher pressure peak. The higher

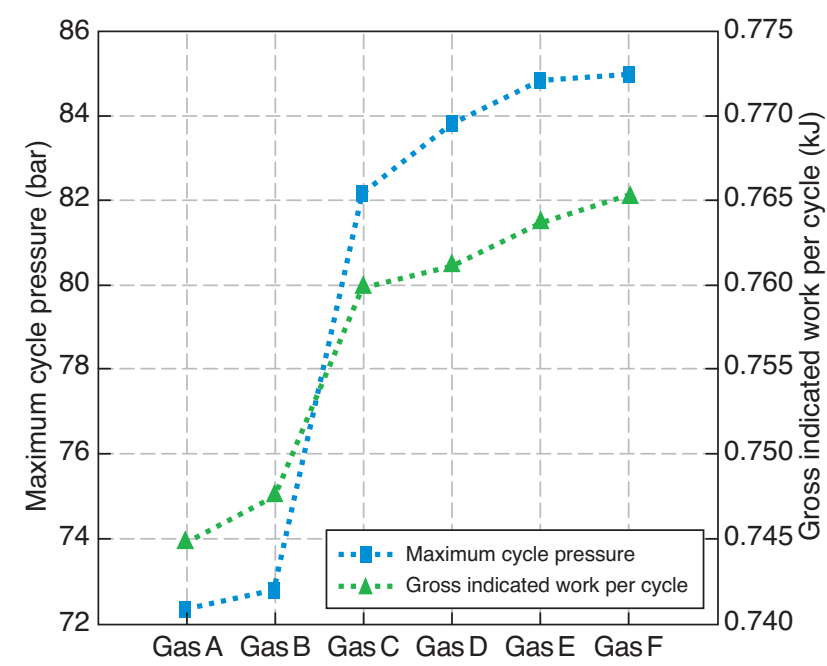

Figure 5

Maximum cycle pressure and gross indicated work per cycle for different gas fuels at $T_{\mathrm{IVC}}=420 \mathrm{~K}$.
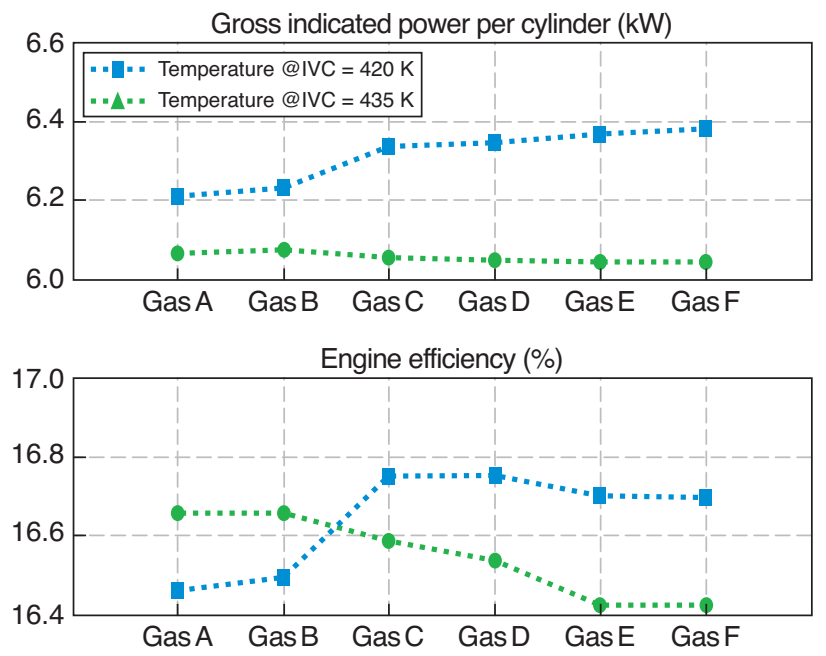

Figure 6

Gross indicated power and engine efficiency for different gas fuels at $T_{\mathrm{IVC}}=420 \mathrm{~K}$ and $435 \mathrm{~K}$. in-cylinder pressure would lead to higher cycle work. This is shown in Figure 5.

It is important to know that in this case, using Gas A (pure methane), and Gas B as fuel leads to unfavorable engine performance but other fuels seem to be suitable. These fuels ignite about $9 \mathrm{CA}$ later in comparison to Gas F; also their maximum pressure value is significantly lower than other gas fuels.

In the next step, the temperature at IVC was set to $435 \mathrm{~K}$. The results are shown in Figure 4c. As predicted, the combustion will occur earlier for each fuel in comparison to the previous conditions. It is because of higher inlet temperature. The primary reaction rates will increase when the initial temperature is higher so the combustion occurs earlier. However, it should be mentioned that increasing initial temperature would increase inlet mixture specific volume and decrease the amount of entering fuel. These variations will affect on engine power and efficiency. This is clearly shown in Figure 6.

For fuel Gases C, D, E, and F higher initial temperature would decrease engine efficiency and indicated power. This is because of the engine is fed with less amount of fuel as specific volume rises at higher temperature. Although this theorem is true for fuel Gases A, B but there is another ruling phenomena that makes an inverse result. The best time for combustion initiation is near TDC, which will lead to higher output power. At $T_{\mathrm{IVC}}=420 \mathrm{~K}$, Gases A and B, undergo an abnormal combustion after TDC. Increasing initial temperature, causes these gases ignite at much proper time near TDC and this suitability overcomes the reverse effect of higher specific volume.

\subsection{Effect of Engine Speed}

The maximum temperature of in-cylinder mixture for different gas fuels at different engine speeds are shown in Figure 7.

Increasing engine speed causes a small variation in the maximum temperature/pressure of all fuels except Gas A and $\mathrm{B}$, which show a sharp decrease and undergo an abnormal late combustion. However, it should be mentioned that the engine speed variation is relatively small. It can be seen that there is a meaningful relation between fuel $W N$ and the value of maximum pressure/temperature. The fuels with higher $W N$ ignite earlier and have higher peak in temperature/pressure diagram. By increasing engine speed from 700 to $1100 \mathrm{rpm}$, the Crank Angle that peak pressure occurs at, changes about 2.2 CA for Gas F but Gas A has wide variation of about $11.5 \mathrm{CA}$.

Values of gross indicated work are shown in Figure 8. Typically, gross indicated work is a semi-parabolic function of engine speed and has a maximum, in a specific point. The figure shows three different trends. While Gas A and B have their maximum gross indicated power at $800 \mathrm{rpm}$, Gas $\mathrm{C}$ gets 


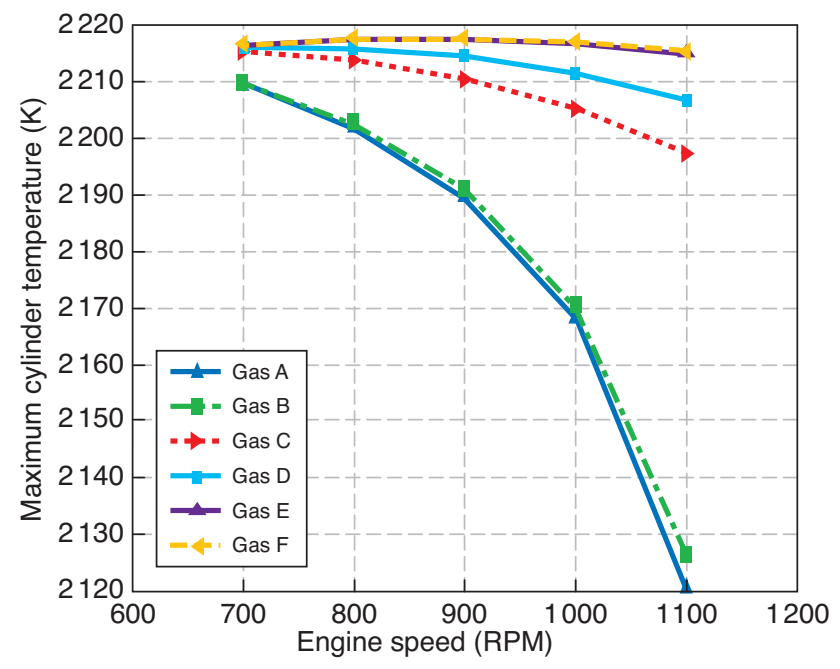

Figure 7

Maximum cylinder temperature for different gas fuels.

its maximum value at $1000 \mathrm{rpm}$ and other gas are still in their positive slope in 700-1 $100 \mathrm{rpm}$ range, so their maximum values occur at $1100 \mathrm{rpm}$. The gross indicated work is typically used to calculate the Mean Effective Pressure (MEP). The variations in MEP are just like that of Figure 8 for indicated work. The value of MEP is proportional to fuel $W N$ when engine speed is greater than 800 and for less than 800-rpm condition, the proportional relation become inverse. Engine speed of $800 \mathrm{rpm}$ is a pivot point where all gas fuels show high similarity.

This difference is exactly because of variation in ignition timing as shown in Figure 9. Increasing engine speed would postpone SOC. Engine speeds affects directly on time-dependent parameters. As increasing engine speed does not have a significant effect on in-cylinder temperature and pressure variations, the mechanism initiation reactions, simultaneously start in all cases. The time interval between this moment and SOC is almost the same in different engine speeds but in higher speeds, this time interval is equivalent to more Crank Angles; therefore, SOC occurs later in higher engine speeds.

Gross indicated power is one of the main parameters that can be used to compare engine performance in different conditions. This parameter is shown in bar diagram of Figure 10. The gross indicated power increases from the order of $4.4 \mathrm{~kW}$ to about $6.6-7 \mathrm{~kW}$ as engine speed grows through 700 to $1100 \mathrm{rpm}$. Although the variation in the value of work done by engine cycle in different speeds, affect the indicated power value but the decreasing engine cycle time has a leading rule that results in higher engine power.

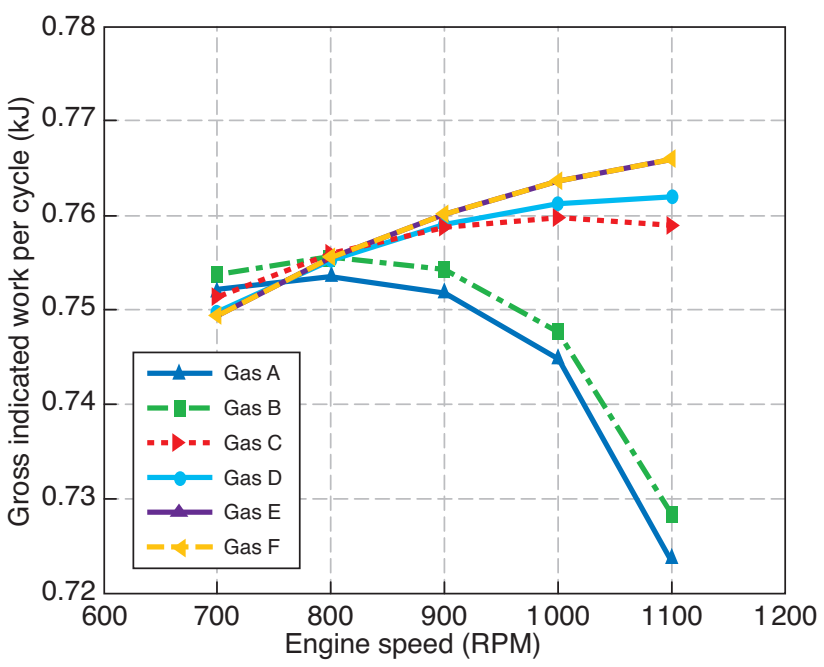

Figure 8

Gross indicated work per cycle for different gas fuels.

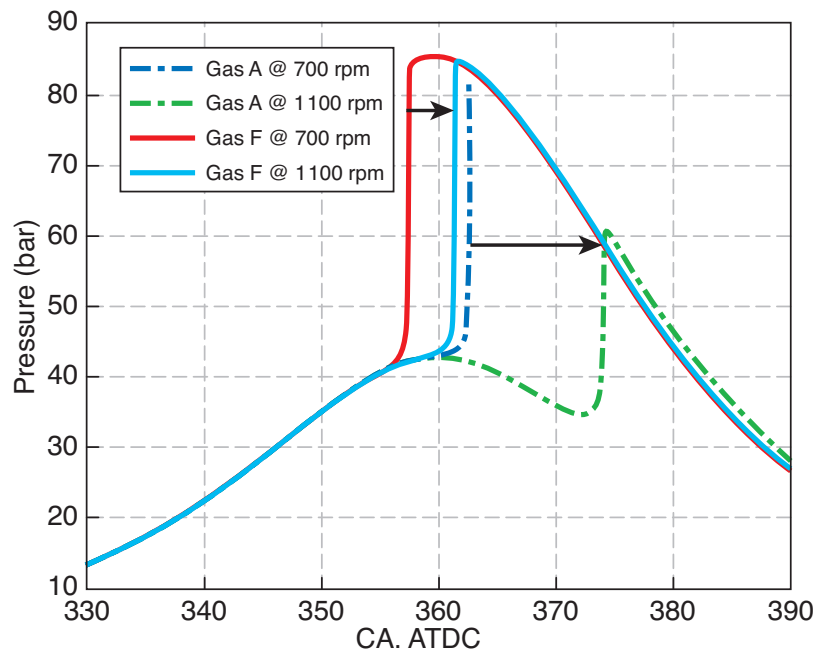

Figure 9

Pressure trend variation for Gas A and F from 700 to $1100 \mathrm{rpm}$.

Figure 11 shows engine power values relative to power of engine fueled with pure methane (Gas A). At 700 and $800 \mathrm{rpm}$, the differences are lower than $0.5 \%$, but as engine speed increases, this difference raises to 5-6\%. Notable difference in high engine speed is somehow related to methane unfavorable combustion.

Adding ethane and propane to methane will increase its $W N$ as shown in Table 1, because these two hydrocarbons have higher LHV per volume $\left(\mathrm{MJ} / \mathrm{m}^{3}\right)$ than methane. On the other side, higher ethane and propane content generally leads to advanced SOC due to their lower auto-ignition temperature 


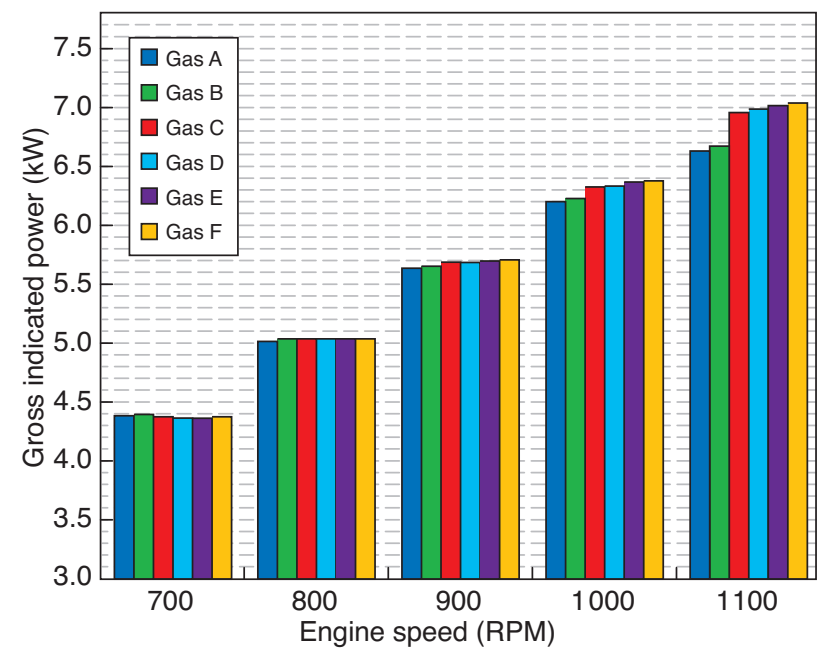

Figure 10

Gross indicated power for different gas fuels.

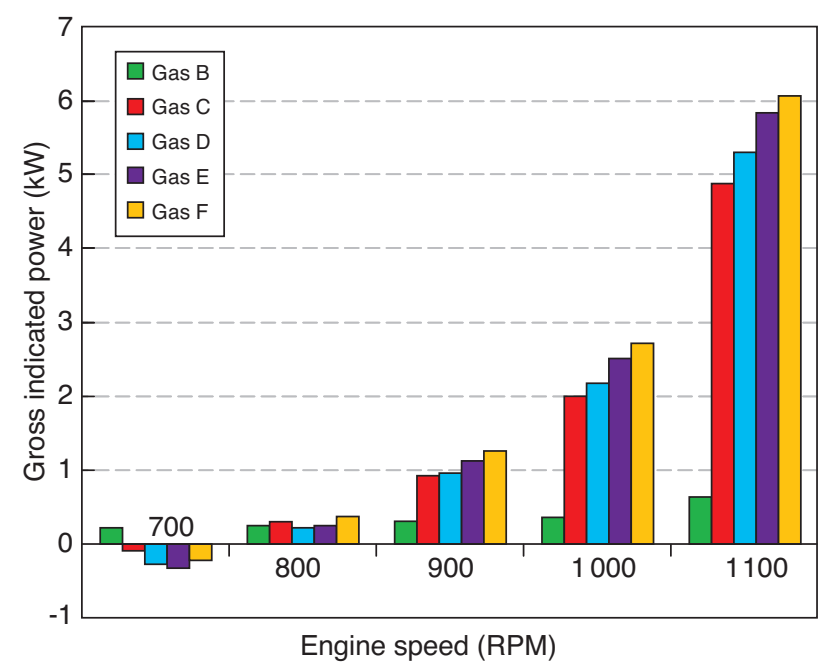

Figure 11

Relative gross indicated power for different gas fuels by pure methane (Gas F).

and thus higher engine output. This is thoroughly discussed in the explanation related to Figure 8. Therefore, it is logical to conclude that there will be a relation between fuel $W N$ and engine power.

In order to study on the influence of fuel $W N$ on engine performance, the gross indicated power variations are plotted due to fuel $W N$ in different engine speeds, shown in Figure 12. It can be seen that there is a regular linear pattern between engine power and fuel $W N$ at each engine speed expect $1100 \mathrm{rpm}$ that Gas A and B experience an abnormal combustion. This linear relation can be presented as:

$$
\text { Engine Power }=C_{1} \cdot W N+C_{2}
$$

A same relation was previously presented for diesel engines fueled with Natural Gas [21]. $C_{1}$ and $C_{2}$ can be obtained by simple linearization methods. These constants are shown in Table 3 for each engine speed.

TABLE 3

Values of $C_{1}$ and $C_{2}$ in Equation (17)

\begin{tabular}{c|c|c|c}
\hline Engine speed (RPM) & $C_{1}$ & $C_{2}$ & Norm of residuals \\
\hline 700 & -0.0085919 & 4.7647 & 0.014126 \\
\hline 800 & 0.005907 & 4.7725 & 0.010529 \\
\hline 900 & 0.03224 & 4.2433 & 0.032602 \\
\hline 1000 & 0.082409 & 2.6311 & 0.086187 \\
\hline 1100 & 0.19719 & -1.9152 & 0.23942 \\
\hline
\end{tabular}

The last column shows that the linear relation can describe the phenomena with appropriate accuracy but the $1100 \mathrm{rpm}$ case should be treated with more considerations.

It is practical to use cubic curve fitting in order to acquire the relation between $C_{1}-C_{2}$ and engine speed $(N)$ :

$$
\begin{aligned}
C_{1} & =0.004399\left(\frac{N}{100}\right)^{3}-0.10272\left(\frac{N}{100}\right)^{2} \\
& +0.81409\left(\frac{N}{100}\right)-2.1828 \\
C_{2} & =-0.1998\left(\frac{N}{100}\right)^{3}-4.6655\left(\frac{N}{100}\right)^{2} \\
& -36.309\left(\frac{N}{100}\right)+98.854
\end{aligned}
$$

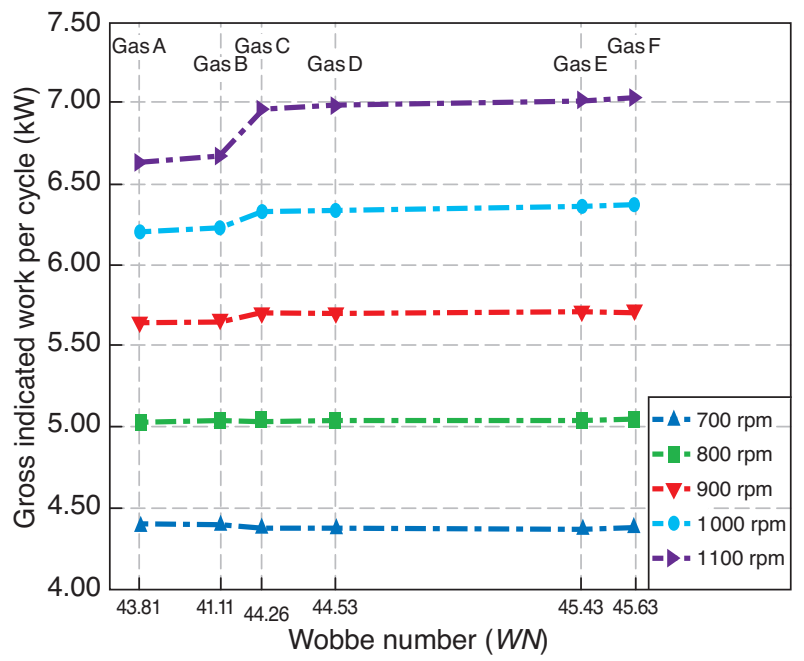

Figure 12

Gross indicated power due to fuel $W N$ for different engine speeds. 


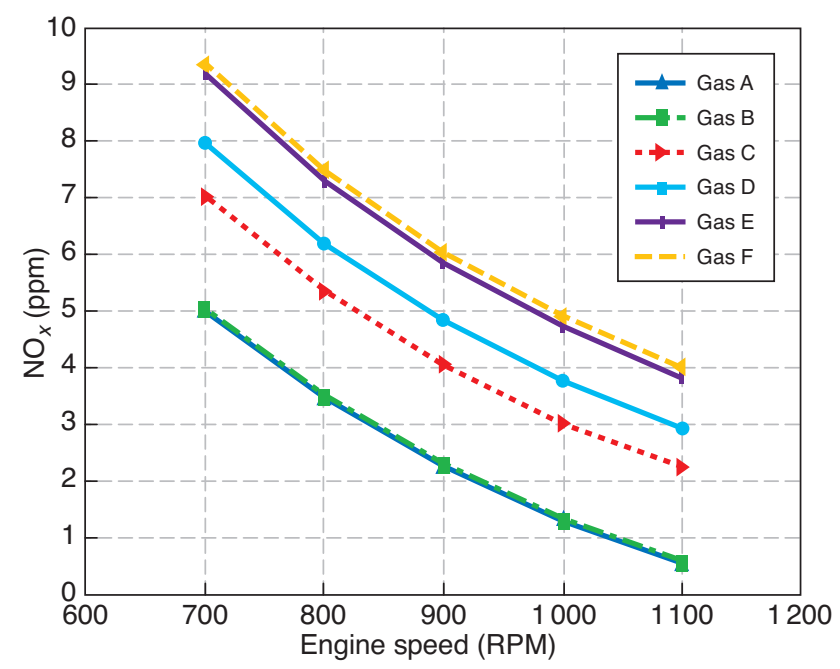

Figure 13

$\mathrm{NO}_{x}$ emission for different gas fuels.

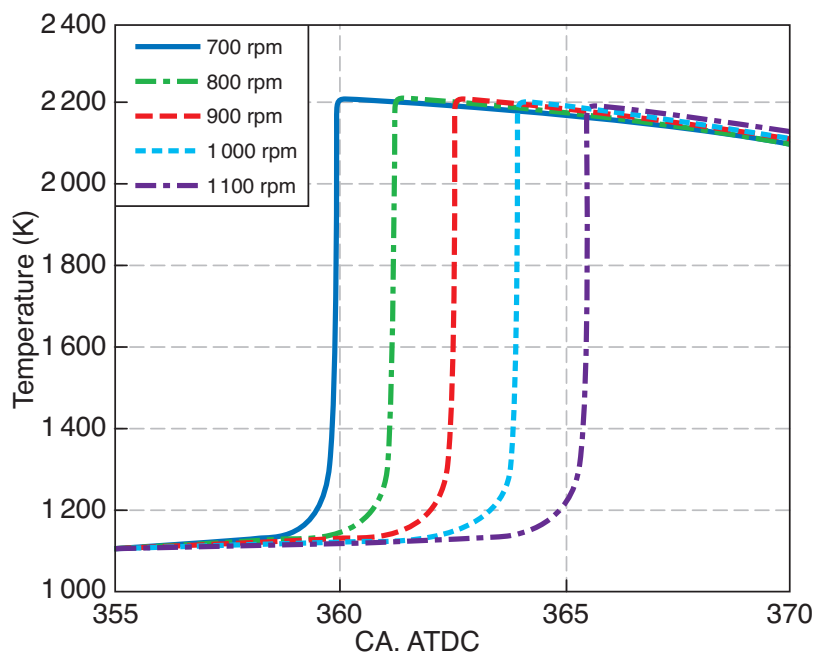

Figure 14

Temperature trend variations for Gas $\mathrm{C}$ in different engine speeds.
Simulated $\mathrm{NO}_{x}$ emission from the engine is shown in Figure 13. The main source of $\mathrm{NO}_{x}$ in HCCI engines is thermal $\mathrm{NO}_{x}$; so it is obvious that the amount of $\mathrm{NO}_{x}$ is directly related to in-cylinder temperature trend. Two parameters affect this relation:

- maximum cylinder temperature;

- duration of high temperature.

In comparison of different compositions, the first parameter is important. Figures 7 show the maximum temperature of different fuels. The sequence is exactly reproduced in Figure 13. The fuels with high $W N$ make high in-cylinder temperature and therefore higher $\mathrm{NO}_{x}$ is expected.

The second parameter is the main reason for negative slope of the curves. Temperature trend variations of Gas $\mathrm{C}$ in different engine speeds is plotted in Figure 14. It is seen that there is no significant difference between maximum temperature values for different engine speeds but the duration of high temperature is longer for low engine speeds. For instance, the duration of high temperature at $700 \mathrm{rpm}$ is about 6 CA longer than the case of $1100 \mathrm{rpm}$.

\section{CONCLUSION}

This study was preformed to investigate the effects of Natural Gas composition on the performance of an HCCI engine. The principal conclusions can be summarized as follows:

- natural Gas HCCI engine is sensitive to fuel composition. Varying fuel composition affects the auto-ignition characteristics of in-cylinder mixture and the performance of the engine;
- fuels with higher amount of ethane and propane ignite earlier in comparison to others;

- gas composition affects on pressure/temperature trends of an HCCI engine. Engine fueled with the highest $W N$ ("Gas F") displays 12.6 bar higher peak pressure value in comparison to the one fueled with pure methane ("Gas A") in specified condition;

- natural gas compositions with higher WN seem to have higher pressure/temperature peak value;

- indicated power will rise as initial temperature increases for gases A and B because increasing initial temperature causes these gases ignite at a much proper time near TDC but for fuel Gases C, D, E, and F higher initial temperature would decrease engine efficiency and indicated power. The ignition time has the leading rule in this phenomenon;

- gross indicated power shows a linear relation to fuel $W N$ at selected range of engine speed. It can be defines as:

$$
\text { Engine power }=C_{1} \cdot W N+C_{2}
$$

- HCCI engine $\mathrm{NO}_{x}$ is directly proportional to maximum in-cylinder temperature and duration of high temperature. Higher fuel $W N$ and lower engine speed usually lead to higher amount of $\mathrm{NO}_{x}$ emission.

\section{ACKNOWLEDGMENT}

The authors express their deep appreciation acknowledgment to Dr. M. Shahbakhti for his useful guidance. 


\section{REFERENCES}

1 Shahangian N., Keshavarz M., Jazayeri S.A. (2009) Analysis of HCCI Engine Operation with Diesel Like Fuels, Oil Gas Sci. Technol. 64, 4, 521-532.

2 Jahanian O., Jazayeri S.A. (2010) The Effects of Using Formaldehyde as an Additive on the Performance of an HCCI Engine Fueled with Natural Gas, ASME International Mechanical Engineering Congress \& Exhibition (IMECE2010), Vancouver, Canada, November 12-18.

3 Jahanian O., Jazayeri S.A. (2009) A Comprehensive Study on Natural Gas HCCI Engine Response to Different Initial Conditions via a Thermo-Kinetic Engine Model, ASME Internal Combustion Engine Division Fall Technical Conference (ICEF2009), Lucerne, Switzerland, September 27-30.

4 Morsy M.H. (2007) Ignition Control of methane Fueled Homogenous Charge Compression Ignition Engines Using Additives, Fuel 86, 533-540.

5 Onishi S., Hong Jo S., Shoda K., Kato S. (1979) Active ThermoAtmosphere Combustion (ATAC) - A New Combustion Process for Internal Combustion Engines, SAE paper 790501.

6 Noguchi M., Tanaka T., Takeuchi Y. (1979) A Study on Gasoline Engine Combustion by Observation of Intermediate Reactive Products during Combustion, SAE paper 790840.

7 Najt P.M., Foster D.E. (1983) Compression-Ignited Homogenous Charge Combustion, SAE paper 830264.

8 Thring R.H. (1989) Homogenous Charge Compression-Ignition (HCCI) Engines, SAE paper 892068.

9 Ryan T.W., Callahan T. (1996) Homogenous Charge Compression Ignition of Diesel Fuel, SAE paper 961160.

10 Fiveland S.B., Christensen M., Johansson B., Hiltner J., Mauss F., Assanis D.N. (2001) Experimental and Simulated Results Detailing the Sensitivity of Natural Gas HCCI Engines to Fuel Composition, SAE paper 2001-01-3609.

11 Stanglmaier R.H., Roberts C.E. (1999) Homogenous Charge Compression Ignition (HCCI): Benefits, Compromises, and Future Engine Applications, SAE paper 1999-01-3682.

12 Alizadeh Attar A. (1997) Optimization and Knock Modeling of a Gas Fueled Spark Ignition Engine, $P h D$ Thesis, the University of Calgary Alberta.

13 Clark N.N., Mott G.E., Atkinson C.M., deJong R.J., Atkinson R.J., Latvakosky T., Traver M.L. (1995) Effect of Fuel Composition on the Operation of a lean-Burn Natural Gas Engine, SAE paper 952560.

14 King S. (1992) The Impact of Natural Gas Composition on Fuel Metering and Engine Operational Characteristics, SAE paper 920593.

15 Kubesh J., King S.R., Liss W.E. (1992) Effect of Gas Composition on Octane Number of Natural Gas Fuels, SAE paper 922359.

16 Blazek C.F., Freeman P., Bailey B.K., Colucci C. (1994) Fuel Composition Effects on Natural Gas Vehicle Emissions, 207th ACS National Meeting-Division of Fuel Chemistry, San Diego, USA, March 13-17.

17 Sakai T. (1996) Effect of Natural Gas Composition on Engine Performance and Exhaust Emissions, Jidosya Kennkyu 18, 1, 23-26.

18 Matthews R., Chiu J., Hilden D. (1996) CNG Composition in Texas and the Effects of Composition on Emissions, Fuel Economy, and Driver-Ability of NGV's, SAE paper 962097.
19 Lee Y., Kim G. (1999) Effect of Gas Compositions on Fuel Economy and Exhaust Emissions of Natural Gas Vehicles, $K S A E 7$ 8, 123-131.

20 Min B.H., Chung J.T., Kim H.Y., Park S.S. (2002) Effects of Gas Composition on the Performance and Emissions of Compressed Natural Gas Engines, KSME 16, 2, 219-226.

21 Kim K., Kim H., Kim B., Lee K., Lee K. (2009) Effect of Natural gas Composition on the Performance of a CNG Engine, Oil Gas Sci. Technol. 64, 2, 199-206.

22 Landau M. (2005) Paper Study on the Effect of Varying Fuel Composition on Fuel Supplied to Detroit Diesel Gas Engines, Southern California Gas Company Technical Report 2005.

23 Salaun M., Kouakou A., Da Costa S., Da Costa P. (2009) Synthetic Gas Bench Study of a Natural Gas Vehicle Commercial Catalyst in Monolithic Form: On the Effect of gas Composition, Appl. Catal. B: Env. 88, 386-397.

24 Smith G.P., Golden D.M., Frenklach M., Moriarty N.W., Eiteneer B., Goldenberg M., Bowman C.T., Hanson R.K., Song S., Gardiner Jr W.C., Lissianski V.V., Qin Z., GRI 3.0 Mechanism, Gas Research Institute, available at: http://www.me.berkeley.edu/gri_mech.

25 Jahanian O., Jazayeri S.A. (2009) A Numerical Investigation on the Effects of $\mathrm{H}_{2} \mathrm{O}_{2}$ and $\mathrm{CH}_{2} \mathrm{O}$ Additives on the Performance of an HCCI engine Fueled with Natural Gas, 6th International Conference of Internal Combustion Engine (ICICE2009), Tehran, Iran, November 17-19 (in Persian).

26 Jahanian O., Jazayeri S.A. (2009) A Thermo-Kinetic Model Base Study on Natural Gas HCCI Engine Response to Different Initial Conditions, III International Congress on Combustion Engines, Opole, Poland, June 22-24.

27 Chang J., Guralp O., Filipi Z., Assanis D., Kuo T.W., Najt P., Rask R. (2004) New Heat Transfer Correlation for an HCCI Engine Derived from Measurements of Instantaneous Surface Heat Flux, SAE paper 2004-01-2996.

28 Heywood J.B. (1988) Engine Design and Operating Parameters, in Internal Combustion Engine Fundamentals, McGraw-Hill Book Company, Singapore.

29 Kuo K.K.Y. (1986) Review of Chemical Kinetics, in Principles of Combustion, John Wiley \& Sons, Inc., Singapore.

30 http://homepages.vub.ac.be/ akonnov/science/mechanism/texts/ mech04.txt

31 Flowers D., Aceves S., Westbrook C.K., Smith J.R., Dibble R. (2001) Detailed Chemical Kinetic Simulation of Natural Gas HCCI Combustion: Gas Composition Effects and Investigation of Control Strategies, J. Eng. Gas Turbine. Power 123, 433-439.

32 Nouri R., Mohsenian Rad A.F. (2009) A Study on the Effects of Using CNG on the Efficiency of Internal Combustion Engines, 2nd Conference \& Exhibition on CNG \& related Industries, Tehran, Iran, 26-27 July - Data by Iranian Fuel Conservation Company (IFCO) - (In Persian).

33 Christensen M., Johansson B. (1999) Homogenous Charge Compression Ignition with Water Injection, SAE paper 1999-010182.

34 Shahbakhti M., Koch C.R. (2007) Thermo-Kinetic Combustion Modeling of an HCCI Engine to Analyze Ignition Timing for Control Applications, 2007 Spring Technical Meeting Combustion Institute/Canadian Section, Banff, Canada, May 13-16.

35 Checkel M.D, Dale J.D. (1986) Computerized Knock Detection From Engine Pressure Records, SAE paper 860028. 
36 Fiveland S.B., Assanis D.N. (2002) Development and Validation of a Quasi-Dimensional Model for HCCI Engine Performance and Emissions Studies under Turbocharged Conditions, SAE paper 2002-01-1757.

37 Wang Z., Shuai S.J., Wang J.X., Tian G.H., An X.L. (2006) Modeling of HCCI Combustion: From OD to 3D, SAE paper 2006-01-1364.

38 Liss W.E. (1993) Fuel Issues for Gas Engine and NGVs, Windsor Workshop on Alternative Fuels, Gas Research Institute Publication, pp. 441-461.
39 Quelch G.E., Gallo M.M., Schaefer III H.F. (1992) Aspects of the Reaction Mechanism of Ethane Combustion. Conformations of Ethylperoxy Radical, J. Am. Chem. Soc. 114, 8239-8247.

40 Sanderson R.T. (1971) Chemical Bonds and Bond Energy, Academic Press, USA.
Final manuscript received in March 2011 Published online in November 2011 


\section{APPENDIX A: THERMODYNAMIC PROPERTIES}

$L H V$ of a gaseous mixture can be obtained by Equation (18) where $i$ represents the mass fraction of component $x_{i}$. LHV of light hydrocarbons are listed in Natural Gas handbooks. Nitrogen has zero heating value [37]:

$$
L H V=\sum x_{i} L H V_{i}
$$

Specific Gravity $(S G)$ is the ratio of the gas density to the air density. It can be calculated as:

$$
S G=\frac{M}{M_{\text {air }}} \quad M_{\text {air }}=28.97 \mathrm{~kg} \cdot \mathrm{mol}^{-1}
$$

Wobbe Number $(W N)$ is especially an important parameter in NG fuels. It is a measure of energy flow rate through an orifice [38] and defines the chemical energy that will flow through an orifice with a given pressure drop. It is calculated by dividing the volume heating value of the fuel by the square root of specific gravity:

$$
W N=\frac{\rho . L H V}{\sqrt{S G}}
$$

To describe natural gas characteristics based on its energy content, $W N$ is used. $W N$ increases when the content of the non-methane hydrocarbon increases. This increase results from the higher densities of the non-methane hydrocarbons. The $W N$ decreases when the inert gases concentration rises. Different $W N$ causes change in stoichiometric $\mathrm{A} / \mathrm{F}$ ratio which affects equivalence ratio. Equivalence ratio is of primary importance in the engine operation.

\section{APPENDIX B: COMBUSTION KINETICS REVIEW}

Alkane combustion is initiated by abstraction of a hydrogen atom from the alkane $(R H)$ to form the alkyle radical $(\dot{R})$ and hydrogen radical $(\dot{\mathrm{H}})$ [39]:

$$
R H \rightarrow \dot{R}+\dot{\mathrm{H}}
$$

These radicals propagates the combustion reaction with oxygen $(\dot{\mathrm{O}})$ and hydroxyl $(\dot{\mathrm{O}} \mathrm{H})$ radicals. These radicals are mainly produced via:

$$
\begin{aligned}
& \mathrm{O}_{2} \rightarrow 2 \dot{\mathrm{O}} \\
& \dot{\mathrm{H}}+\mathrm{O}_{2} \rightarrow \dot{\mathrm{O}}+\dot{\mathrm{O}}
\end{aligned}
$$

For $\mathrm{CH}_{4}, \mathrm{C}_{2} \mathrm{H}_{6}$ and $\mathrm{C}_{3} \mathrm{H}_{8}$, the initiation reactions are:
a) $\mathrm{CH}_{4} \rightarrow \dot{\mathrm{C}} \mathrm{H}_{3}+\dot{\mathrm{H}}$
b) $\mathrm{C}_{2} \mathrm{H}_{6} \rightarrow \dot{\mathrm{C}}_{2} \mathrm{H}_{5}+\dot{\mathrm{H}}$
c) $\mathrm{C}_{3} \mathrm{H}_{8} \rightarrow \dot{\mathrm{C}}_{3} \mathrm{H}_{7}+\dot{\mathrm{H}}$

The main propagation reactions are:

$$
\begin{aligned}
& \mathrm{CH}_{4}+\dot{\mathrm{O}} \rightarrow \dot{\mathrm{C}} \mathrm{H}_{3}+\dot{\mathrm{O}} \mathrm{H} \\
& \mathrm{CH}_{4}+\dot{\mathrm{H}} \rightarrow \dot{\mathrm{C}}_{3}+\mathrm{H}_{2} \\
& \mathrm{CH}_{4}+\dot{\mathrm{O}} \mathrm{H} \rightarrow \dot{\mathrm{C}} \mathrm{H}_{3}+\mathrm{H}_{2} \mathrm{O} \\
& \mathrm{C}_{2} \mathrm{H}_{6}+\dot{\mathrm{C}} \mathrm{H}_{3} \rightarrow \dot{\mathrm{C}}_{2} \mathrm{H}_{5}+\mathrm{CH}_{4} \\
& \mathrm{C}_{2} \mathrm{H}_{6}+\dot{\mathrm{O}} \mathrm{H} \rightarrow \dot{\mathrm{C}}_{2} \mathrm{H}_{5}+\mathrm{H}_{2} \mathrm{O} \\
& \mathrm{C}_{2} \mathrm{H}_{6}+\dot{\mathrm{H}} \rightarrow \dot{\mathrm{C}}_{2} \mathrm{H}_{5}+\mathrm{H}_{2} \\
& \mathrm{C}_{2} \mathrm{H}_{6}+\dot{\mathrm{O}} \rightarrow \dot{\mathrm{C}}_{2} \mathrm{H}_{5}+\mathrm{OH} \\
& \mathrm{C}_{3} \mathrm{H}_{8}+\dot{\mathrm{C}} \mathrm{H}_{3} \rightarrow \dot{\mathrm{C}}_{3} \mathrm{H}_{7}+\mathrm{CH}_{4} \\
& \mathrm{C}_{3} \mathrm{H}_{8}+\dot{\mathrm{O}} \mathrm{H}_{3} \dot{\mathrm{C}}_{3} \mathrm{H}_{7}+\mathrm{H}_{2} \mathrm{O} \\
& \mathrm{C}_{3} \mathrm{H}_{8}+\dot{\mathrm{H}} \rightarrow \dot{\mathrm{C}}_{3} \mathrm{H}_{7}+\mathrm{H}_{2} \\
& \mathrm{C}_{3} \mathrm{H}_{8}+\dot{\mathrm{O}} \rightarrow \dot{\mathrm{C}}_{3} \mathrm{H}_{7}+\mathrm{OH}
\end{aligned}
$$

It can be seen that the most important phenomena in these reactions is $\mathrm{C}-\mathrm{H}$ bond dissociation energy for breaking alkane to alkyle radical. Lower bond dissociation energy leads to easier alkyle radical formation so the molecule will ignite in lower temperature. The $\mathrm{C}-\mathrm{H}$ bond dissociation energy for alkane hydrocarbons used as fuel in this paper is listed in Table 1B.

TABLE $1 B$

C-H bond dissociation energy in light alkanes [40]

\begin{tabular}{c|c}
\hline Alkane & C-H bond dissociation energy kcal/mole \\
\hline $\mathrm{CH}_{4}$ & 103 \\
\hline $\mathrm{C}_{2} \mathrm{H}_{6}$ & 98 \\
\hline $\mathrm{C}_{3} \mathrm{H}_{8}$ & 95 \\
\hline
\end{tabular}

The $\mathrm{C}-\mathrm{H}$ bond dissociation energy in propane molecule is lower in comparison with ethane and methane, so propane has lower ignition temperature and its oxidation reactions will start earlier than ethane and methane. For the same reason, ethane will ignite earlier in comparison with methane. 